\title{
The Roadmap concept: using early on-treatment virologic responses to optimize long-term outcomes for patients with chronic hepatitis $B$
}

\author{
Edward J. Gane
}

Received: 22 December 2007/ Accepted: 30 May 2008/Published online: 25 July 2008

(c) Asian Pacific Association for the Study of the Liver 2008

\begin{abstract}
Several large observational, longitudinal studies of the natural history of chronic hepatitis B (CHB) have demonstrated that high levels of hepatitis B virus (HBV) replication are associated with long-term risk of cirrhosis, decompensation, hepatocellular carcinoma, and liver-related mortality. The corollary is also true-profound and sustained suppression either spontaneously or during antiviral therapy will prevent disease progression and complications. Multiple analyses of various baseline factors and on-treatment responses have identified the absolute HBV DNA level after 24 weeks of therapy as the best predictor of long-term efficacy. Lower 24-week serum HBV DNA levels after lamivudine, telbivudine, or entecavir are associated with higher rates of maintained HBV DNA nondetectability, ALT normalization, HBeAg seroconversion, and lack of resistance. Patients with undetectable serum HBV DNA levels after 24 weeks have the best long-term outcomes while those with levels remaining above 10,000 copies per $\mathrm{ml}$ are unlikely to benefit from long-term therapy with that particular agent and either the addition or switch to another antiviral agent with increased potency but without cross resistance could be considered at this time point. In the future, improved ontreatment monitoring should facilitate treatment strategies to optimize long-term outcomes among patients receiving oral antiviral therapy for CHB.
\end{abstract}

Keywords Chronic hepatitis B - Roadmap concept . On-treatment response $\cdot$ PCR nondetectability .

Genetic barrier to resistance

E. J. Gane $(\bowtie)$

NZ Liver Transplant Unit, Auckland City Hospital, Auckland, New Zealand

e-mail: edgane@adhb.govt.nz
Two billion people-almost one-half of the world's population-have evidence of exposure to hepatitis B virus. Of these, 400 million have chronic infection with a $20 \%$ lifetime risk of dying from complications of either liver failure or liver cancer. In Asia-Pacific, where more than $80 \%$ of the disease burden lies, an estimated 600,000 die every year from sequelae of chronic hepatitis B-hepatic decompensation and hepatocellular carcinoma. A major advance in the global control of HBV infection has been the successful implementation of universal neonatal vaccination programs in most countries with endemic HBV. By preventing vertical and early horizontal infections, vaccination will eventually eradicate new cases of chronic hepatitis B. However, this will not benefit the large pool with chronic infection, three-quarters of whom live in the Asia-Pacific region.

In the REVEAL study from Taiwan and other large natural history studies of chronic hepatitis B, persistent high levels of HBV replication were associated with increased risk of cirrhosis, liver cancer, and liver-related mortality [1-5]. Sustained suppression of HBV DNA during long-term lamivudine and adefovir therapy is the best predictor of improved long-term outcomes, with increased biochemical, histologic, and serologic responses, and reduced disease progression and complications thereof $[6,7]$. The 2005 APASL Consensus Guidelines states that "the primary goal of treatment for chronic hepatitis B is to permanently suppress HBV" [8].

Sequential monotherapy with nucleos(t)ide analogues remains the current standard of care in most countries, especially in Asia-Pacific where access to combination therapy and pegylated interferon is still limited owing to their costs. Unfortunately, monotherapy is associated with early primary nonresponse and late virologic breakthrough from selection of resistant mutants. Ongoing viral 
replication is soon followed by loss of biochemical and clinical response and associated with disease progression, with increased risks of cirrhosis and complications. Therefore, new individualized strategies are needed to ensure that profound and sustained viral suppression is achieved in order to optimize the long-term outcomes in patients with chronic hepatitis B.

Current treatment guidelines from the major liver associations (2007 AASLD Practice Guidelines, 2008 APASL Consensus Guidelines, and 2002 EASL Guidelines) provide clear recommendations for whom to treat and when to treat and when to stop (either for efficacy or for loss of efficacy) [3, 9, 10]. They also provide recommendations on how to monitor for resistance. However, these guidelines provide very little information on the use of on-treatment responses (other than management of resistance). In other viral infections including HIV and $\mathrm{HCV}$, early on-treatment virologic responses have been demonstrated to be accurate predictors of long-term outcomes to therapy and are now used routinely to optimize therapy in these conditions. Early stopping rules reduce unnecessary costs and morbidity from treatment sideeffects while early predictors of response provide positive feedback, leading to better patient adherence to long-term therapy.

The predictive value of both baseline factors and early on-treatment virologic and biochemical responses have now been analyzed for most approved medications except for standard interferon. Although most of these data were accumulated through small pilot studies or retrospective analyses, the most comprehensive data were collected prospectively during the recent GLOBE study, which represents the largest study to date of antiviral therapy against chronic hepatitis B [11].

In this study, the absolute serum HBV DNA level after 24 weeks of treatment was the most accurate predictor of longterm efficacy (ALT normalization, HBV DNA nondetectability, $\mathrm{HBeAg}$ seroconversion in $\mathrm{HBeAg}$ positive patients, and lack of resistance). The predictive value of 24-week serum HBV DNA level was greater than for virologic responses after 4 and 12 weeks, ALT responses at any time and baseline HBV DNA and ALT levels $[12,13]$. This held true for both lamivudine and for telbivudine, although more patients treated with telbivudine achieved maximal on-treatment viral suppression due to the greater potency of this agent.

Responses at 24 weeks were divided into three categories, according to associated long-term outcome. Complete virologic responders were defined as those patients who had undetectable HBV DNA by PCR at 24 weeks ( $<60 \mathrm{IU} /$ $\mathrm{ml})$. These patients had the highest rates of sustained PCR nondetectability $(>90 \%)$ and ALT normalization $(80 \%)$ after 2 years and the lowest rates of viral breakthrough $(<5 \%)$. Partial virologic responders were defined as those patients with definite virologic response but who did not achieve complete viral suppression at 24 weeks-HBV DNA was detectable but $<2000 \mathrm{IU} / \mathrm{ml}$. Finally, inadequate (or suboptimal) virologic responders were defined as those patients with persisting moderate or high levels of $\mathrm{HBV}$ DNA $(>2000 \mathrm{IU} / \mathrm{ml})$ despite 24 weeks therapy. In these patients, efficacy endpoints were poor at 2 years with 30 $60 \%$ developing antiviral resistance.

For all efficacy endpoints, the best cut-off for predictability (positive predictive value and negative predictive value) was nondetectability of $\mathrm{HBV}$ DNA by PCR ( $<300 \mathrm{cpm}$ or $<50 \mathrm{IU} / \mathrm{ml})$.

These associations between 24-week viral suppression and sustained responses at 1 and 2 years were irrespective of treatment allocation, although both overall response rates and positive predictive values were higher in the telbivudine group reflecting the greater antiviral potency of this drug. The corollary was also true-the negative predictive value of 24-week HBV DNA levels was less in the telbivudine group, that is, patients who failed to become PCR nondetectable after 24 weeks of telbivudine were more likely to attain PCR nondetectability, ALT normalization and less likely to become resistant than patients on lamivudine who remained PCR detectable at 24 weeks.

Similar relationships between 24-week viral loads and long-term efficacy have also been reported for entecavir, a nucleoside analogue with similar antiviral potency against HBV [14].

Finally, an inverse relationship was observed between the 24-week viral load and risk of resistance after both 1 and 2 years of treatment with lamivudine and telbivudine $[11,12]$. This is not true for adefovir, for which the best predictor of long-term outcomes was the 48-week HBV DNA level [15]. This difference is thought to reflect the slow onset of action and relatively weak antiviral potency of adefovir, when administered at $10 \mathrm{mg}$ per day.

The Roadmap concept (see Fig. 1) uses 24-week virologic responses to individualize ongoing management in patients with chronic hepatitis $\mathrm{B}$, in order to minimize long-term resistance and improve long-term efficacy. Patients who achieve a complete response at week 24 can

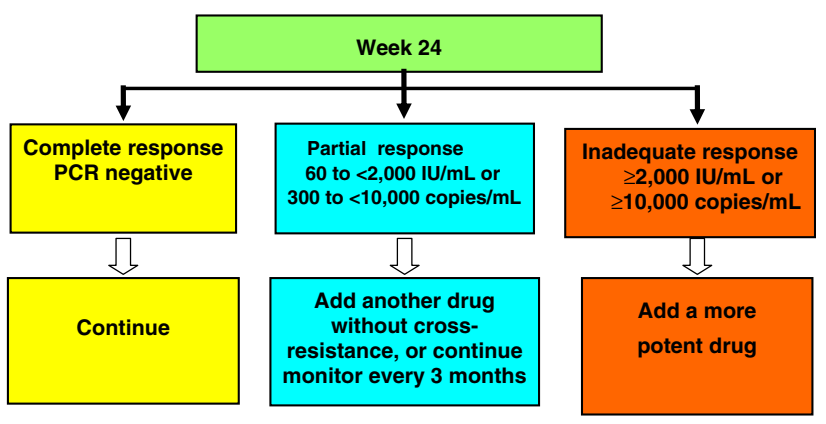

Fig. 1 The Roadmap concept 
remain on their current therapy and the interval for monitoring can be extended to 6-monthly at the physician's discretion. Patients who achieve only a partial response at week 24 need to have their therapy changed. For those being treated with a drug with a high genetic barrier to resistance, such as adefovir or entecavir, they should continue their treatment beyond 48 weeks, undergoing repeated viral level testing at 3-month intervals. Monitoring interval should remain at 3 months and response reassessed after 48 weeks. If their response remains partial or becomes inadequate at week 48 , their therapy should be changed. If response becomes complete at week 48 , the therapy can be continued. For those receiving a drug with a medium (telbivudine) or low genetic barrier to resistance (lamivudine, emtricitabine), addition of a second drug without cross-resistance should be considered at 24 weeks. Patients with an inadequate virologic response at week 24 should be switched to a different, more effective drug, if available. Alternatively, a second drug can be added, preferably one without cross-resistance to the first drug. Then, the patient should be monitored every 3 months up to week 48. If the viral level falls to undetectable levels at week 48, the viral load testing can be done every 6 months. However, patients who have advanced disease should continue to be monitored every 3 months, regardless of the nature of their response.

Caveats to the Roadmap concept are that it is not applicable to patients receiving immunomodulator therapies such as thymosin-alpha, conventional interferon, or pegylated interferon. The applicability is best for patients receiving nucleos $(\mathrm{t})$ ide analogues with low genetic barrier to resistance, such as lamivudine, emtricitabine, clevudine, and telbivudine. The role of the Roadmap concept in patients receiving nucleos(t)ide analogues with high genetic barrier to resistance, such as tenofovir and entecavir, has yet to be determined. Despite improved antiviral potency with tenofovir and entecavir, rates of $\mathrm{HBeAg}$ seroconversion achieved in patients with $\mathrm{HBeAg}$ positive CHB remain suboptimal [16, 17]. Further studies may support the use of the Roadmap concept to optimize $\mathrm{HBeAg}$ seroconversion with all nucleos(t)ide analogues, irrespective of genetic barrier to resistance. It has been designed for the treatment-naïve patient receiving nucleos(t)ide analogue monotherapy. Its applicability to those started on combination therapy or those with established antiviral resistance is unknown given the high rate of cross resistance among current therapies.

\section{Conclusion}

The level of serum HBV DNA predicts the natural history of $\mathrm{CHB}$ in individual patients. Sustained reduction in HBV
DNA levels during long-term nucleos(t)ide analogue therapy is associated with lower rates of progression to cirrhosis and complications thereof. Clinical studies have shown that early and profound suppression of viral levels lead to improved outcomes and less antiviral resistance. Profound and sustained inhibition of viral replication is therefore the most important goal of antiviral therapy in chronic hepatitis B. The roadmap provides physicians with the ability to achieve this goal by measuring viral levels during treatment to assess response to oral therapy. Early monitoring of the virologic response to oral nucleos(t)ide therapy is essential in order to identify patients with suboptimal responses so that an appropriate change in therapy can be initiated. Use of the strategies outlined in the Roadmap concept should permit clinicians to provide individualized treatment throughout the course of therapy and thus enhance long-term patient outcomes.

\section{References}

1. Chen CJ, Yang HI, Su J, Jen CL, You SL, Lu SN, et al. Risk of hepatocellular carcinoma across a biological gradient of serum hepatitis B virus DNA level. JAMA 2006;295:65-73.

2. Iloeje UH, Yang HI, Su J, Jen CL, You SL, Chen CJ. Predicting cirrhosis risk based on level of circulating hepatitis B viral load. Gastroenterology 2006;130:678-686.

3. Chen G, Lin W, Shen F, Ileoje UH, London WT, Evans AA. Past HBV viral load as a predictor of mortality and morbidity from HCC and chronic liver disease in a prospective study. Am J Gastroenterol 2006;101:1797-1803.

4. Yuan HJ, Yuen MF, Wong DK, Sablon E, Lai CL. The relationship between HBV-DNA levels and cirrhosis-related complications in Chinese with chronic hepatitis B. J Viral Hepat 2005; 12:373-379.

5. Yuen MF, Yuan HJ, Wong DK, Yuen JK, Wong WM, Chan AO, et al. Prognostic determinants for chronic hepatitis B in Asians: therapeutic implications. Gut 2005;54:1610-1614.

6. Mommeja-Marin H, Mondou E, Blum MR, Rousseau F. Serum HBV DNA as a marker of efficacy during therapy for chronic HBV infection: analysis and review of the literature. Hepatology 2003;37:1309-1319.

7. Yuen MF, Sablon E, Hui CK, Yuan HJ, Decraemer H, Lai CL. Factors associated with hepatitis B virus DNA breakthrough in patients receiving prolonged lamivudine therapy. Hepatology 2001;34:785-791.

8. Liaw YF, Leung N, Kao J-H, et al. Asian-Pacific consensus statement on the management of chronic hepatitis B: a 2008 update. Hepatology Int 2008 (in press).

9. Lok ASF, McMahon BJ. AASLD practice guidelines. Chronic hepatitis B. Hepatology 2007;45:507-539.

10. EASL international consensus conference on hepatitis B. 13-14 September, 2002: Geneva, Switzerland. Consensus statement. J Hepatol 2003;38:533-540.

11. Lai C, Gane E, Liaw Y-FMD, Thongsawat S, et al. Telbivudine versus lamivudine for patients with chronic hepatitis B. N Engl J Med 2007;357:34-46.

12. DiBisceglie A, Lai CL, Gane E, et al. Telbivudine GLOBE trial: maximal early HBV suppression is predictive of optimal two-year efficacy in nucleoside-treated hepatitis B (Abstract). Hepatology 2006;44(Suppl 1):230A-231A. 
13. Keeffe E, Zeuzem S, Koff R, Dieterich D, Gane E, et al. Report of an international workshop: Roadmap for management of patients receiving oral therapy for chronic hepatitis B. Clin Gastroenterol Hepatol 2007;5:890-897.

14. Gish R, Lok A, Chang T, et al. Entecavir therapy for up to 96 weeks in patients with $\mathrm{HBeAg}$-positive chronic hepatitis B. Gastroenterology 2007;133:1437-1444.

15. Hadziyannis S, Tassopoulos N, Heathcote E, et al. Adefovir Dipivoxil 438 Study Group. Long-term therapy with adefovir dipivoxil for HBeAg-negative chronic hepatitis B for up to 5 years. Gastroenterology 2006;131:1743-1751.

16. Chang T-T, Gish RG, de Man R, et al. A comparison of entecavir and lamivudine for HBeAg-positive chronic hepatitis B. New Engl J Med 2006;354(10):1001-1010.

17. Heathcote J, Gane E, DeMan R, Lee S, Flisiak R, et al. Tenofovir DF for Versus Adefovir Dipivoxil for the Treatment of $\mathrm{HBeAg}$ Positive (+) Chronic Hepatitis B. Boston: AASLD; 2007. 